\title{
ANÁLISIS DEL PERSONAJE EN EL CINE Y EN LOS VIDEOJUEGOS. INMERSIÓN Y EMPATÍA
}

\author{
Guillermo TATO
}

Guionista y escritor

\section{RESUMEN}

El videojuego ha heredado el lenguaje y las formas del cine en un nuevo medio basado tanto en lo visual como en lo interactivo, produciendo una combinación innovadora en el terreno de la narrativa. Los primeros títulos que se lanzaron tenían como baremo su cercanía al cine, pero mantenían una aspiración que no hacía justicia a las posibilidades del videojuego en su vertiente más comunicativa, tal y como le sucedía al cine en sus primeros años.

La influencia del cine en el videojuego deja abierta la cuestión de una narración que, en la práctica totalidad del cine comercial, se considera como eje vertebrador de la obra. El guion es el primer paso para entender el sentido y el objetivo de la película y en su epicentro está el personaje, que da sentido a la historia a través de la empatía generada en el espectador y que, a su vez, representa y verbaliza las funciones ocultas que pudiera albergar la película.

¿Cabe hablar de la misma forma del personaje cuando estamos en un entorno interactivo donde el jugador tiene a veces un peso similar en el desarrollo de la narración al del creador del juego? ¿Cómo debemos cambiar nuestra percepción de la narración cuando el personaje toma caminos ni siquiera previstos por el guionista? El artículo trata de responder a estas preguntas que se generan cuando relacionamos un medio con posibilidades todavía por explorar como el videojuego con otro como es el cine.

Para ello, se realizará un análisis de los videojuegos narrativos y veremos la función que puede ejercer en cada uno de los mismos el personaje principal y hasta qué punto puede incluirse en la escritura del videojuego la interpretación del jugador cuando adopta este papel. Nos planteamos hasta qué punto jugador y personaje son entidades separadas, si el videojuego es una actividad de interpretación de un papel o interpreta la forma de jugar del jugador, si es una labor de interpretación o de empatía.

Palabras clave: Cine, videojuegos, personaje, narración, ludología, disonancia ludonarrativa, ludonarratalogía, guion, interpretación, interactividad.

Key words: Cinema, videogames, narration, ludology, ludonarrative dissonance, script, interactivity. 


\section{INTRODUCCIÓN}

"Todo lo que se necesita en una película es un arma y una mujer".

Pese a que en la mítica cita de Jean-Luc Godard no menciona en ningún momento al personaje principal de la película, sin duda lo podemos encontrar en los entresijos de la misma. La base de la gran mayoría de películas reside precisamente en quién pasa a convertirse en el sujeto de esa oración, es decir, el protagonista. En esa famosa cita se resume de forma certera el motor de un guion cinematográfico a través del objeto de deseo (representado como la mujer) y los medios para conseguirlo (basados en el conflicto que simboliza la pistola). El espectador se sumerge en esa narración a través de los ojos del personaje, de su identidad y de sus problemas y necesidades. Es decir, se convierte a su vez en sujeto de esas mismas necesidades. El personaje se convierte en un vehículo imprescindible que nos permite adentrarnos por propia voluntad en esa consecución de imágenes en movimiento a la que llamamos cine y a la que le conferimos habitualmente un sentido narrativo con el que darle una coherencia global. Por extensión, nos hace tener los mismos deseos y entender las estrategias que tiene ese protagonista para conseguir sus fines. Pese a que en el videojuego no es siempre necesario ese tipo de protagonista (como demuestran títulos como Tetris, Clash Royale o Gran Turismo donde lo único que se necesita es un jugador que los juegue), cuando está presente y su función busca los mismos objetivos narrativos que en el cine, se rige por los mismos principios que determinan la cita de Godard. Incluso con mayor razón. El videojuego en esencia es precisamente eso, con especial énfasis en la pistola. Solo se necesita un pequeño retoque que le otorgue esa nueva dimensión que representa la interactividad. Todo lo que se necesita en un videojuego es un arma, una mujer y una mecánica que nos permita interactuar con ese universo. $Y$ en este caso, con un sentido ligeramente modificado, el sujeto puede convertirse en el personaje o bien en el jugador. El presente artículo tratará, entre otras cosas, de discernir entre esas dos identidades a la hora de encarar un videojuego de corte narrativo.

En un estudio que intenta analizar el videojuego confrontado con el cine, una de las grandes dificultades que se plantea viene a la hora de comparar elementos aparentemente comunes, como es el caso del personaje. Pero llegados a este punto cabe destacar que esa comparación directa entre videojuegos y cine no es del todo apropiada. El cine (entendiéndolo como largometrajes de ficción) se puede englobar dentro de un marco mucho más genérico como es el audiovisual. Es un lenguaje concreto realizado a través de un medio mucho más amplio: el uso de la imagen en movimiento para ser emitida o proyectada. El cine convive en su espacio con otros formatos que también emplean el audiovisual con distintos fines y con estructuras y elementos muy diferenciados en un sentido formal y de uso. Estaríamos hablando de informativos, documentales, emisiones en directo de eventos deportivos o series. En cambio, del otro lado tenemos a los videojuegos, que forman en sí mismos una masa comparable a la del propio audiovisual del que el videojuego toma elementos. Dentro del videojuego, al igual que dentro del audiovisual, podemos encontrar diferentes formas de gestionar o negociar con ese sistema de comunicación. Tenemos juegos que son puzles, aventuras gráficas, juegos de móviles, juegos de estrategia, MOBAs o simuladores deportivos. Pese a ser todos ellos videojuegos, deben identificarse con una forma propia de entender el lenguaje $y$, en especial, de hacer uso de los elementos que lo definen como tales. No hablamos de distintos géneros (algo 
que nos permitiría diferenciar elementos narrativos y de puesta en escena, pero teniendo siempre la idea comunicativa compartida), sino de distintos medios de expresión. Por tanto, si realizamos una comparativa directa entre cine y videojuegos estaríamos cometiendo un error grave de interpretación al no comparar masas del mismo calibre. Por ese motivo, este artículo se centra en aquellos videojuegos en los que la inmersión narrativa tiene una implicación directa tanto en el objetivo del juego como en la interpretación del mismo por parte del jugador. No se trata solo de solucionar mecánicas lúdicas que nos otorgan una recompensa, sino que la narrativa debe guiar las decisiones que tomamos y sea a su vez una de las recompensas obtenidas por el jugador.

Una vez establecido ese marco de estudio (el cine narrativo frente al videojuego narrativo), podemos intentar encontrar unos parámetros que nos ayuden a comparar la identidad del espectador frente al texto cinematográfico con la identidad del jugador frente al videojuego. Esta identidad se realiza a través de la figura del personaje principal (incluso en los casos de protagonismo compartido o coral, donde la variedad de personajes realiza la misma labor de mediación con el universo narrativo actuando como una entidad única). Para establecer estos puntos de comparación entre ambas interpretaciones del personaje, desmenuzaremos algunos elementos que nos ayudarán a interpretarlos y a confrontarlos para ver qué diálogo se produce entre ellos y en cada uno de los medios en los que transcurren.

\section{2. ¿QUIÉN SOY?}

Es la primera pregunta clave que nos plantea cualquier tipo de narración. Una pregunta que definirá el punto de vista en el que nos va a situar como lectores, espectadores o jugadores. La narración normalmente gira alrededor de un individuo (o un objeto/animal dotado de personalidad) que sufre un problema, una perturbación en la estabilidad de su vida y que debe solucionar de forma ineludible mediante una estrategia que definirá no solo el ritmo de la narración y de los acontecimientos, sino que nos ayudará a interpretar su personalidad (a través de las estrategias que no ha elegido, por ejemplo, entendemos también qué tipo de personaje es). Este personaje nos guía a través de una trama activa (interna o externa) y nos posiciona dentro del universo de la narración. Le da sentido (en relación casi siempre a las motivaciones y objetivos del personaje). Este universo y este personaje, como objetivo último, no se explican tan solo a ellos mismos, sino que también nos permiten extrapolarlos a nuestro propio mundo y nuestras vivencias: es decir, ese mundo inventado funciona como reflejo de las necesidades y deseos que tenemos como seres humanos, lo que permite potenciar la empatía que sentimos hacia el personaje. En las narraciones más clásicas, el eje principal alrededor del que gira todo es el personaje y su lucha (fútil o épica) contra su propia humanidad y contra los poderes de la naturaleza y el mundo que nos rodea y en el que estamos obligados a habitar.

¿Cómo aplicamos esa definición del personaje en un videojuego? En el cine es un proceso más natural y asumido a lo largo de sus más de cien años de historia, ya que la narratología está mucho más instaurada como mecanismo básico de funcionamiento. Pero en el videojuego, esos anhelos no se vuelcan únicamente en el personaje, sino en todo lo que representa o lo que es capaz de hacer. De esta forma, muchos videojuegos se enfocan en nuestro deseo de ser más fuertes, poderosos o hábiles de lo que somos en la vida real. Pero se trata de un deseo mediado, más propio del jugador y no tanto del personaje, para quien gracias a su propia naturaleza es una situación asumida y que no le supone el mismo 
tipo de reto o satisfacción (pongamos por ejemplo a Kratos en God of War). Esa es una variable propia del videojuego frente al cine, ya que existe ese doble objetivo o motivación lúdica/mecánica respecto al personaje dentro de la trama. A diferencia de como sucede en el cine, donde el espectador tiene un rol más pasivo en el desarrollo de la historia (no nos referimos en este punto a las tareas interpretativas, donde el espectador de cine es incluso más activo que el del videojuego). El jugador, sin embargo, puede imponer su propia personalidad al personaje del juego, solaparla e, incluso, ignorarla por completo, realizando a su vez su propia lectura y valoración de la historia del videojuego paralela a la pensada originalmente por el desarrollador. Hay juegos que dotan al personaje de un objetivo más directo y llano, sin mediación de personalidad alguna del personaje, para que el jugador se apropie únicamente del objetivo inmediato, pero pueda imponerle su propia personalidad lúdica. Sería el caso de Zelda. Breath of the Wild donde el transcurso del juego en sí está por encima siempre de la trama, que es bastante simple y directa. En estos casos no hay conflicto de objetivos, pero en otros como en GTA IV sí se puede producir un conflicto inmediato con la personalidad de Niko y la forma de jugar (y por tanto, de los objetivos lúdicos) que plantee el jugador al apropiarse de ese texto interactivo.

Por tanto, cabe destacar la diferencia entre estos personajes de videojuegos. Algunos son meros vehículos que nos permiten vivir experiencias enmarcadas dentro de una trama lineal y un universo concretos. Estos personajes nos introducen ante todo dentro de mecánicas específicas que, pese a tener una apariencia de trasfondo narrativo (como Super Mario y su rescate de la princesa), no son más que piruetas que están siempre al servicio de la mecánica y las reglas del juego. Estos personajes no tienen más personalidad que la que transmiten sus diseños. No se enfrentan a dilemas, ni cargan con la pesada losa de ser humanos. Existen simplemente para ayudarnos a vivir una experiencia lúdica, y no para plantearnos su sentido narrativo. Otros personajes, en cambio, se nos presentan como sujetos directos de una narración, con unas necesidades concretas que provienen del universo que les rodea y que destapan una mayor profundidad psicológica en el personaje.

Pero antes de llegar a ese punto, el texto debe ayudarnos a entender quiénes somos y qué papel tenemos en ese universo, desconocido hasta este momento. En el cine, este proceso requiere de un acto completo dentro del guion, generando un goteo de información constante que nos van ofreciendo tanto el mundo en el que se desarrolla como el propio personaje/actor. Se trata, ante todo, de hacer que el espectador entienda de forma inmediata no solo de qué va ir la película, sino cómo es el personaje con el que nos vamos a identificar y cuáles son sus objetivos. Se plantea una situación en la que sufre algún tipo de desgracia que nos lo ponga de su lado y queramos que lo solucione, viviendo desde su perspectiva todas sus vicisitudes y estrategias. En el videojuego, esa presentación suele ser más pragmática y está, ante todo, orientada al objetivo del personaje y a darnos una guía de qué estrategias (inmediatas y objetivas) tendremos a nuestra disposición. Hasta el punto de que en multitud de títulos se abusa de una fórmula narrativa en la que nuestro personaje despierta en un lugar desconocido sin recordar quién es ni su pasado. Esto sucede en juegos como Silent Hill 2, Bioshock o el mencionado Zelda. Breath of the Wild, donde el personaje se convierte en una tabla rasa sobre la que iremos añadiendo detalles y experiencias a medida que las vaya descubriendo el personaje. De esta forma, se produce un mecanismo de creación del personaje inverso al normal y en el que el apartado lúdico cobra mucho más protagonismo. Pero en la mayoría de ocasiones, el trasfondo o las necesidades del personaje tienden a ser casi siempre externas: recuperar un objeto, salvar a alguien o acabar 
con una entidad malvada que nos persigue. Los conflictos internos tienden a estar siempre camuflados, si no completamente desconectados.

Esto también se debe a que el personaje del videojuego no funciona como en una narración cinematográfica (o incluso literaria), donde su materia prima es la personalidad que lo ha creado y que afecta a todo lo que le rodea. En un videojuego el personaje tiene funciones mucho más pragmáticas en gran parte de los casos. Cogiendo un manual de escritura de videojuegos como Video Game Storytelling: What Every Developer Needs to Know about Narrative Techniques escrito por Evan Skolnick, descubrimos que el diseño narrativo del personaje supone tan solo una pequeña parte a la hora de su creación, junto con elementos como el concepto artístico, el modelado, las animaciones, el audio o su implementación en el universo del juego. Es interesante este último punto, porque nos define al personaje como un muñeco más dentro del videojuego, uno con valores e identidad especial, pero cuya presencia se define por el volumen y las relaciones causales que va a producir con el resto de los elementos del juego. No habla de los valores narrativos de la implementación del personaje en el juego (como sí sucedería en un guion cinematográfico), señal de la enorme importancia del valor lúdico del personaje como elemento esencial en la relación entre el jugador y el videojuego.

\section{PERSONALIDAD: ARQUITECTURA HUMANA}

En el cine, la personalidad de un personaje está siempre vinculada con la empatía. Con esa capacidad humana de ponernos en el pellejo de otra persona y hacer como nuestros sus problemas. Lo que se suele buscar es que esa empatía sea positiva, con el propósito de facilitar la aproximación del espectador mediante unos problemas y conflictos que puede comprender y hacer suyos. Pero también se puede jugar con todo lo contrario, con una antipatía inicial del personaje para poder ir adentrándonos poco a poco en sus motivaciones y de esa forma hacernos capaces de entender a personajes con motivaciones e identidades casi opuestas a las que tenemos en nuestra vida. Esa personalidad se construye, esencialmente, a través de un estudio psicológico del personaje. No tenemos un personaje que se defina solo por ser bueno o malo, rico o pobre, listo o tonto... necesitamos el matiz humano que nos defina realmente su actitud hacia la vida, y eso normalmente viene a través de sus debilidades. En gran parte de los casos, los personajes se definen principalmente por sus debilidades. El miedo a estar solo, a la muerte de seres queridos, a perder el status quo, a que descubran una mentira... La debilidad nos acerca a los personajes y posibilita de forma mucho más clara esa empatía. De acuerdo, siempre tendremos películas de Steven Seagal en las que el personaje es una mera excusa para orientar la acción que se desarrollará en la historia, pero son películas mucho más cercanas a los videojuegos que hemos descartado al inicio del artículo. De hecho, gran parte de los primeros videojuegos beben directamente de esta fuente, con juegos como Double Dragon o Street Fighter.

Esa debilidad del personaje es un rasgo que en el videojuego se suele traducir en algo demasiado objetivo y que afecta única y exclusivamente a la mecánica de juego. De hecho, el videojuego en sí habitualmente trabaja más con la grandeza del personaje que con su debilidad. O mejor dicho, de cómo hacer de un personaje hundido, un héroe. Si antes no podía hacer doble salto, a lo largo del juego lo conseguirá. Si antes no podía detectar a los enemigos, tarde o temprano podrá comprar algo con lo que mejorarlo. Algo que se ve en muchos juegos actuales, como Horizon Zero Dawn, donde la protagonista va superando 
sus debilidades y convirtiéndolas en fortalezas. En su caso, el motor de la historia es otro estándar de los videojuegos: la venganza, como mecanismo inmediato de empatía para posicionarnos del lado del personaje.

McKee explica que "el diseño de los personajes comienza con la organización de sus dos aspectos principales: la caracterización y la verdadera personalidad." Esta verdadera personalidad es la que iremos descubriendo a lo largo de la película, a veces mediante detalles sutiles, y otras mediante un arco de transformación del personaje que se nos revela al final. El caso es que siempre debe haber una máscara en el personaje, no solo a través de una revelación narrativa, sino en la forma final en la que actúa un personaje. En los videojuegos, esa verdadera personalidad suele ser la que le aporta el jugador mediante su forma de jugar y de encarar la historia. Se nos tiende a mostrar al personaje tal y como es, sin ninguna máscara que oculte su verdadero yo. No hay truco, simplemente porque el verdadero yo es el jugador que lo maneja. Pero, ¿es el jugador responsable de llevar a cabo la auténtica naturaleza del personaje? ¿Qué interpretaciones narrativas se pueden sacar de su forma de jugar?

En otros casos se acude a un recurso narrativo propio del videojuego: las secuencias narrativas de vídeo en las que se detiene la acción lidia y se abre un paréntesis narrativo con reglas en algunos casos muy diferenciadas: estamos hablando de las cinemáticas. En estas, no solo se avanza en la acción como quieren los desarrolladores (y muchas veces con cambios de tono drásticos respecto a lo que acabamos de jugar, como en el caso de Final Fantasy VII, donde en todos los combates podemos resucitar a los personajes muertos, pero no en la cinemática de la muerte de uno de los personajes principales). Estas escenas muestran también la "auténtica" personalidad del personaje, donde le vemos tomar decisiones por su cuenta. Decisiones que tendrán un efecto decisivo en la trama, y que pueden no tener nada que ver con las decisiones lúdicas que acabamos de tomar durante la partida. De nuevo, ¿quién es el auténtico personaje? ¿El que impone el desarrollador o el que crea el jugador a través de sus decisiones y sus estrategias? $Y$, en ese segundo caso, ¿cómo podría el diseñador del juego tenerla en cuenta para que haya una coherencia narrativa? Son dudas abiertas, todavía sin respuesta y que muestran claramente ese choque directo que se produce entre la narratología y la ludología, el estudio de los videojuegos a través de diferentes perspectivas.

La personalidad de un personaje debe oscilar entre esas dos necesidades: las que le ha otorgado el desarrollador y las que le aporta el juego en sí (o la que le aporta el jugador con sus decisiones). Debido a esto se suelen producir incoherencias narrativas como las que vemos en un juego como el reciente reinicio de la saga Tomb Raider, donde se nos presenta a una Lara Croft inocente y atormentada por su pasado, mientras que en las partes jugables es (somos) capaz de matar a sangre fría a centenares de personas (camufladas bajo el amparo de términos como "enemigo", "soldado" o "rival"). Este hecho se conoce como disonancia ludonarrativa. El término hace referencia a esa brecha que se genera entre el ritmo de la narración y las necesidades del juego, lo cual se traduce a su vez en incoherencias narrativas bastante graves. Otro ejemplo sería el desarrollo de los personajes de Watch Dogs 2: unos jóvenes hackers que sin embargo son capaces de realizar masacres tiroteando a todo aquel que se interponga en su camino, rompiendo de esta forma por completo cualquier atisbo de personaje que hubiera podido haber. Todo esto nos lleva a lo mismo: las consecuencias en el personaje de matar a otros seres humanos y la necesidad en muchos de los juegos en que la parte lúdica nos obligue a realizar semejantes crímenes. Obviamente, la medida del 
asesinato es relativa, ya que en gran parte dependerá del contexto que hayamos creado para ello. Esto se puede ver en películas como Rambo: First Blood Part II o en un videojuego como Wolfenstein. Pero nos deja más dudas en otros casos, como Uncharted (que aspira a tener un desarrollo más profundo del personaje).

Otro tipo de desarrollo del personaje es aquel que es consciente de las reglas del género en el que juega. No solo tenemos las películas de acción que comentábamos, sino que también existen los protagonistas de los westerns, las películas de terror o incluso en ciertos subgéneros de la comedia. Dentro de estos últimos podríamos encajar a los personajes de aventuras de Lucasarts como The Secret of Monkey Island o Maniac Mansion, donde el personaje es más consciente de sí mismo como parte de un género con el que está jugando (en todos los sentidos). Los matices y la construcción del personaje están orientados en esos casos a las necesidades propias del género dentro del que se enmarcan. Los protagonistas de una película de terror siempre son planos, pero porque ante todo responden a unas necesidades para la construcción del suspense. Son meras marionetas que tienen que bajar al sótano o acudir a ese lugar oscuro y siniestro. Algo similar sucede en los videojuegos, donde tenemos la sensación de que la trama/acción nos va a llevar a un sitio concreto solo para vivir esa situación única, ese tiroteo espectacular o ese vídeo que nos revelará muchas cosas de la trama y del personaje.

\section{EL OBJETIVO DEL PERSONAJE Y EL OBJETIVO DEL JUGADOR}

¿Cuándo acaba el personaje y en qué momento entro yo, jugador, dentro del marco narrativo del videojuego? ¿A partir de qué punto lo que estoy haciendo es decisión del personaje (o imposición del desarrollador) o es completamente mía y propia del texto lúdico que estoy creando? ¿Cuál es el propósito último de la narración, explicarse a sí misma o ayudarme a vivir una experiencia lúdica? De nuevo, nos encontramos con los dos mismos límites que nos han ido acompañado a lo largo del artículo. El videojuego como narración o como mecanismo lúdico.

En el guion cinematográfico el objetivo del personaje se utiliza como una forma no solo de dinamizar la historia con un propósito final, sino también de darle sentido último con el que dotar de un cierto orden a un universo aparentemente caótico. Ese objetivo centra la trama, haciendo que todo lo que la rodea gire en torno a su propósito. Es decir, tematiza todos los conflictos y las relaciones que moldean el vínculo del personaje con el universo que le rodea. Si tenemos a un personaje que necesita recuperar el amor de su hija, de todas las opciones dramáticas que imperan en ese universo en el que habitan, nos centraremos en aquellas orientadas al amor paternal, la confianza o la capacidad de dar libertad a un ser querido. Nuestro personaje orbitará alrededor de esa necesidad personal, pudiendo realizar estrategias variadas que o bien nos lleven la película a una comedia (como por ejemplo deshacerse del novio de su hija que es quien se la está quitando), o bien con reflexiones más profundas que tiendan más al drama (la imposibilidad de conectar con generaciones posteriores). Pese a que el objetivo pueda ser algo objetivo y claro, siempre debe esconder reflexiones humanas y únicas del personaje. Porque al final del camino, el objetivo es lo que nos define al personaje (y más aún el motivo real, no el aparente, por el cual está persiguiendo dicho objetivo).

En el videojuego nos encontramos casi siempre con objetivos unidimensionales que no incluyen esa reflexión interna por parte del personaje. En un juego como Horizon Zero Dawn, 
Aloy (la protagonista) busca vengarse por algo objetivo y directo, sin segundas lecturas ni valoraciones. Algo similar a lo que experimenta Aiden Pearce en Watch Dogs con la muerte de su sobrina. El personaje clásico del videojuego tiende a depararnos pocas sorpresas en cuanto a su personalidad (los motivos reales). Y de nuevo, por los mismos motivos que hemos visto antes. Porque esa motivación interna es el propio jugador. Es imposible disociarlas porque los objetivos del personaje y del jugador pueden ser muy distintos $y$, sin embargo, tener que cohabitar en un mismo texto lúdico-narrativo. En una película eso es imposible porque la aportación del espectador es indiferente al texto en sí. Únicamente puede realizar una interpretación personal, pero que no afecta al desarrollo del guion. No obstante, en los videojuegos siempre hay que añadir el objetivo del jugador al objetivo del personaje. Y estos no siempre tienen por qué coincidir. Tomemos por ejemplo del caso de GTA IV. En él, nos ponemos en el papel de Niko Bellic, un veterano de la guerra de Bosnia recién llegado a Liberty City y cuyo propósito inicial es ayudar a su primo Roman, siendo la venganza el motivo real que descubriremos más adelante (de nuevo la venganza y esta vez incluso como objetivo interno). Pues bien, el jugador puede coger todo ese trasfondo narrativo para simplemente dedicarse a dar vueltas por la ciudad o tratar de conseguir el máximo número de estrellas de persecución policial sembrando el caos en Liberty City. En todos los casos es el mismo personaje en el mismo universo con, a priori, los mismos objetivos. Y, sin importar el camino que sigas (el tipo de Niko Bellic que estés interpretando a través de tu juego), la historia seguirá siendo exactamente la misma.

¿Es posible crear personajes más maduros que adopten la forma en la que son jugados (interpretados) como una parte esencial de su psicología? Hasta ahora es algo que no se ha conseguido (incluyendo aquí todos los juegos lanzados por Telltale Games como referente de esa afirmación), pero sin duda sería necesario para el bien de la narratología dentro del videojuego. No solo por el bien de la historia y del videojuego como plataforma seria de explicarlas, sino con el propósito de conferir una mayor credibilidad y humanidad a sus personajes, algo que nos conducirá de forma más precisa a la empatía. Si las acciones no tienen efectos inmediatos en nuestro personaje, el valor dramático del mismo disminuye. El personaje del videojuego tiene un factor orgánico de que carecen la literatura o el cine y es la implicación directa del jugador. Y la narrativa del videojuego todavía no ha sido consciente de forma plena de lo que implica ese poder.

Tomemos otra de las grandes diferencias entre ambos medios. ¿Qué sucede si un personaje de una película no consigue su objetivo? Obviamente que estaríamos ante un final negativo, inamovible, y que debe estar acorde a la tesis que rodea a la lectura del texto. Pero, ¿qué pasa si no lo consigue el personaje de un videojuego? En ese caso, tenemos muchas más variaciones: pantallas de Game Over, finales alternativos, vidas que nos permiten continuar en el mismo punto, partidas grabadas que eliminan todo lo que ha sucedido... El videojuego se adapta a nuestra forma de jugar, haciendo que la no consecución del objetivo sea muchos menos dramática, porque lo importante en realidad es el objetivo último que define a cualquier juego por igual: acabárselo. Ese concepto de "acabarse un juego" es único y propio del medio. Para acabar una película solo hay que estar sentado el tiempo que dura, pero por contra hay videojuegos que por mucho tiempo que lo estés jugando no lo puedes acabar (y no me refiero solo a Dark Souls, sino que es un elemento propio y único del videojuego). Es ahí donde se define el objetivo real del jugador, uno que está mucho más pendiente de la ludología que de la narratología. Por este motivo muchas veces la trama no es más que un objetivo secundario. La capacidad de generar un 
personaje con un objetivo narrativo potentes irá siempre vinculada a la necesidad de asumir el objetivo único del jugador de acabarse el juego (poniendo a prueba su habilidad, su paciencia o su inteligencia).

\section{DESARROLLO Y ELECCIONES: INTERPRETACIÓN FRENTE A CONSTRUCCIÓN}

Un personaje, tras ese primer acto de introducción, se va definiendo de forma cada vez más profunda a través de sus elecciones, bien sean forzadas, voluntarias o incluso por ausencia (no actuar en ciertas situaciones es ya una forma de definir al personaje). Como explica McKee a este respecto, "un personaje será las decisiones que tome sobre las acciones que realice." La clave siempre residirá en la credibilidad de esas decisiones. Una vez el espectador tiene la información y una impresión de cómo es el personaje, el guionista debe permanecer fiel a esa forma de pensar y de vivir. Cualquier cambio brusco puede producir una ruptura emotiva por parte del espectador que le haga dudar de la veracidad de ese personaje, bien porque él mismo no actuaría así o porque no ve razones para que lo haga el personaje. El equilibrio de un guion excelente viene de hacernos entender decisiones complejas o comprometidas como coherentes, gracias a un desarrollo más complejo de un personaje que puede estar en las Antípodas de nuestra forma de pensar, pero que hemos hecho nuestro gracias a esa proyección dramática que realizamos con los personajes. Cuando todos los elementos funcionan a la perfección, la simbiosis es tan perfecta que al salir del cine todavía seguimos sintiéndonos en el pellejo de ese personaje e incluso vemos la vida desde su perspectiva.

En el videojuego, pese a disponer de un arma mucho más poderosa (al fin y al cabo no solo nos sentimos cercanos al personaje sino que somos ese personaje, incluso durante muchas más horas que en una película convencional), no siempre sucede de la misma manera. La pauta principal la marca el diseñador del juego a la hora de proporcionar las herramientas que tendrá a su disposición el jugador cuando interprete al personaje y de interactuar con el universo en el que está inmerso. Pero a diferencia del guionista, el jugador no está obligado a cumplir ningún tipo de lógica interna del personaje más allá del compromiso que se marque él mismo. Por tanto, el personaje se convierte más bien en una carcasa que proyecta nuestras fobias e inquietudes, completamente cambiantes y a veces incluso aleatorias. Deja de ser un personaje real cuyas decisiones deben estar marcadas y regidas por un patrón que se ha ido definiendo a lo largo del primer acto, para convertirse en una marioneta sin identidad definida. Porque esa identidad, en última instancia, se la confiere el jugador durante el acto mismo de jugar, es decir, de darle vida y coherencia a ese universo lúdico.

El principal problema que encontramos en el videojuego viene cuando esas elecciones, por el desarrollo propio de la estructura de la mecánica lúdica (y no tanto de la narrativa), nos lleva a tomar decisiones que van en contra de la personalidad y los principios básicos que identifican a nuestro personaje. Esas situaciones suelen darse por la necesidad de potenciar la interactividad en el juego, dándonos la toma última de decisiones vitales completamente intrascendentes. Ese poder que se le otorga al jugador no es más ni menos que el mismo que puede tener el guionista al escribir un guion, con la salvedad de que dichas decisiones no deben pasar por el juicio del espectador, sino que guionista y espectador se fusionan en una misma entidad que valora y cuestiona su propia obra. $Y$ no lo hace siempre con fines narrativos, sino que en multitud de ocasiones son las consecuencias lúdicas las que van a 
definir en última instancia la elección que tomemos (eso sin tener en cuenta la opción de guardar partida que nos suele permitir ver todas las opciones posibles).

Por ejemplo, en un título como Fallout 3, al poco tiempo de empezar la partida se le da la oportunidad al jugador de tomar una decisión tremendamente dramática. En tus manos tienes la posibilidad de detonar una bomba atómica que arrase por completo una ciudad habitada por un grupo de supervivientes: Megatón. Gente con la que has convivido en tus múltiples paseos por el Yermo, a la que le has comprado provisiones o a la que has ayudado con alguna misión secundaria. No importa lo que hayas experimentado en esa ciudad, ni el vínculo emocional que pueda haber establecido el personaje con esas personas. La opción es siempre la misma para todos los jugadores y todas las partidas sin importar lo que haya sucedido con anterioridad. No importa lo bondadoso o lo indiferente que hayas sido hasta ese momento con los habitantes de Megatón, porque siempre se puede producir un acto terrible de destrucción. ¿Cómo se podría asimilar algo así en una narrativa cinematográfica? ¿Cómo entender que ese personaje de pronto es capaz de cambiar por completo su actitud vital y realizar un acto de ese calibre? Si el personaje decide destruir Megatón, ese hecho no le afecta en nada a su personalidad. No hay remordimientos, ni dudas en su comportamiento posterior. Tampoco hay consecuencias morales, ni un cambio de actitud en la vida del personaje. Puede seguir comportándose igual, como si no hubiera sucedido nada. Se resume una acción dramática en una balanza de pros y contras, en los que como jugadores lo que hacemos es valorar si merece la pena guardar la partida para ver qué se pierde y qué se gana con cada una de las elecciones. Porque en el fondo, la construcción del personaje es lo de menos, lo importante son las consecuencias inmediatas en la mecánica del juego.

El mensaje del usuario Terminator91 en el foro de Meristation define muy bien la frialdad y la ausencia de valoraciones en la construcción del personaje a la hora de tomar este tipo de decisiones en un juego como Fallout 31:

«Anoche guardé la partida justo antes para ver qué pasa al tomar tal decisión, en primer lugar, si hacemos EXPLOTAR la bomba:

Ventajas: Nos dan 500 chapas, nos dan una suite de lujo para vivir en una torre bastante guapa.

Inconvenientes: No hay Megatón, con lo cual los personajes que allí aparecen no los veremos más.

Si DESACTIVAMOS la bomba:

Ventajas: Nos dan 100 míseras chapas, y una choza en Megatón para dormir, los habitantes de Megatón viven.

Inconvenientes: La choza es una mierda, es poco dinero, el señor Burke es nuestro enemigo y más adelante nos hará la vida imposible.»

No se trata tanto de construir a un personaje al cual estamos interpretando (o él nos interpreta a nosotros), sino de ver todas las posibles líneas narrativas que se producen, todas alrededor del personaje y nunca afectándole a él. En estos casos, el personaje es un mero accionador de historias ajenas que presencia como si fuera el espectador de una película

1 Comentario extraído de http://zonaforo.meristation.com/topic/1183733

Quaderns, 12 (2017), pp. 105-117 
o de una novela. En lugar de ser él mismo el protagonista activo. Otro caso especial sería un juego como Until Dawn, donde la mecánica en sí premia la toma de elecciones y el experimentar todas las posibles historias que albergan el universo lúdico que las encierra. Pero este sistema destruye a los personajes porque, en realidad, es uno y todos a la vez, perdiendo por completo su esencia y su posible definición.

Cabe también destacar un juego como Dishonored 2, que no solo nos permite jugar la historia de formas diversas (atacando sin pudor o utilizando estrategias de sigilo para acabarse el juego sin matar a una sola persona), sino que la misma narración se adapta a esos cambios, premiando una estrategia realmente diferente del jugador, muy ligada a su interpretación del personaje y de cómo enfoca el mundo y su problema.

La interpretación es una de las claves esenciales a la hora de dar vida a ese cúmulo de vivencias y actitudes que es el personaje. Cualquier personaje en un guion está pensado para ser interpretado por un actor. La palabra inglesa que se emplea es mucho más explícita e incluso nos conecta directamente el cine con el propio videojuego: play. El actor no solo interpreta, sino que juega a ser otra persona. Tanto en el cine como en el videojuego, la interpretación es un juego de intercambio de roles. Pero mientras que en el videojuego esa interpretación es un medio (y el fin puede ser el mismo personaje, la narración o el jugador), en el cine la interpretación que hace el actor de ese personaje es un fin en sí mismo. El actor se convierte en el personaje.

Llegamos entonces a la esencia de este dilema. La interpretación dramática frente a la interpretación lúdica del personaje. El trabajo del actor es el de dar vida a un personaje que solo existe en el papel, sin su trabajo simplemente no existiría. Y más allá, como comentábamos, el actor se convierte en el personaje hasta el punto de que cuando se produce esa fusión es el actor quien deja de existir. Nos olvidamos de su presencia como entidad que existe en la vida real y le dotamos de la veracidad narrativa, esencial para dar ese salto que nos otorga la veracidad de esa ficción. Por su parte, la función que realiza el jugador a la hora de "interpretar" al personaje es más cercana a la que realiza un titiritero. El personaje puede dejar de tener toda su personalidad para ser un mero mecanismo que nos permita interactuar con el entorno lúdico en el que está inmerso. No se produce tanto una lectura del personaje, como una interpretación de las mecánicas del juego a través del personaje. Pasa a ser un medio en lugar de un fin en sí mismo.

\section{EL DIÁLOGO}

El diálogo es una de las principales conexiones que tenemos con nuestro personaje. Es su forma de expresión más directa y a través de la cual se relaciona no solo con el mundo sino también con el espectador. En un guion cinematográfico, el narrador se expresa con especial fuerza a través de los diálogos a los que se le confiere un valor único. Pero es también un mecanismo que se debe utilizar con cuidado. Cualquier palabra de más puede entorpecer el ritmo de una escena, o bien hacer demasiado farragoso un diálogo entre dos personajes. Como explica McKee, "La esencia del dialogo en pantalla es lo que en el teatro de la antigua Grecia se conocía como stikomythia, el rápido intercambio de breves turnos de palabra." El diálogo no es un simple intercambio de información, sino que es un arte en sí mismo dentro del cual debe existir una definición del personaje (cómo habla y por qué), unas intenciones directas (qué pretende) y en muchas ocasiones unas intenciones ocultas (el subtexto). El diálogo en el cine debe ser conciso, tanto por 
necesidades de ritmo como de tiempo: la película debe durar 90-120 minutos, lo que nos obliga a concretar en ese intercambio de diálogos. Omitimos despedidas al hablar por teléfono, situaciones irrelevantes o cualquier cosa bueno haga avanzar de forma directa la narración o nuestra comprensión de los personajes. Un buen dialogo es aquel expresa el máximo con el mínimo.

El videojuego, en cambio, peca de una absoluta ausencia de concreción en los diálogos. Al contrario, se premia el exceso de diálogo como se puede ver en los largos intercambios que se producen en un juego como Life is Strange. Los personajes se convierten en máquinas parlantes que buscan continuamente la atención del jugador a través de diálogos que se podrían acortar sin problema. Diálogos que a su vez están saturados de información sobre la historia o el universo convirtiéndolos en todavía más farragosos (como sucede en Mass Effect). No se usa el subtexto en ningún momento, y la sutilidad del dialogo desaparece por completo para convertirse en un mero intercambio de información. Incluso, siguiendo con Mass Effect, se explicita la intención del diálogo que elige el jugador para anticipar si la respuesta que damos es más amable o furibunda, sin dejar espacio a los matices (el subtexto), o sin generar un diálogo creíble que no alterne estados emocionales sin motivo alguno (del enfado a la alegría para volver al enfado, sin que la conversación tenga una función narrativa clara). De nuevo, la interactividad brinda herramientas al jugador que entorpecen la lectura del mismo.

Este exceso de información de los videojuegos se plasma en los centenares de cartas, archivos y textos que pululan por un universo como el de Dishonored 2. Tratando de darle mayor trasfondo al universo y explicar todo lo posible, lo que hacen en realidad es llenarlo de ruido narrativo, desviando la atención del jugador no solo de la trama principal, sino también alejando al personaje del foco principal. Lo importante no es el trasfondo en sí de una historia, sino la relación que dicho trasfondo va a tener con nuestro personaje y con su objetivo.

En otros casos, vemos de nuevo el ejemplo del personaje como mero testigo de las historias de los demás, siendo la suya completamente plana y sencilla. Algo que sucede en los juegos de Zelda, en los que tenemos a Link, un héroe silencioso que no dialoga con nadie y que solo se dedica a escuchar a los demás.

\section{CONCLUSIÓN}

El paralelismo entre dos medios como el cine y el videojuego es siempre algo complejo de realizar, ya que sus funciones son muy diferentes. Sin embargo, siempre podremos buscar esos puntos de unión que poco a poco nos los vayan acercando. Hace años pensábamos que un videojuego más cinematográfico era aquel que contenía escenas de vídeo, como The 7th Guest, Night Trap o Black Dahlia. Más tarde lo fueron aquellos juegos que respondían a imitar a películas de acción, como el caso de Uncharted. Pero ninguno de ellos se centraba en lo esencial: otorgarle de coherencia narrativa al personaje principal que vamos a encarnar.

Pero ahora tenemos casos como Firewatch, una narración inmersiva que puede ser lúdica, pero que es ante todo una historia basada en un personaje y la relación estrecha que adquirimos con él, con su drama y cómo queremos que avance su historia a través de pequeños obstáculos que nosotros, los jugadores, debemos solucionar. No tomamos decisiones, pero sí nos obliga a realizar mecanismos lúdicos a la hora de desentrañar tanto la historia como el pasado del personaje. Es decir, no somos el personaje, sino que le ayudamos a que solucione su drama del que somos testigos en primera persona. 
¿Quién es el personaje principal del videojuego? ¿Nosotros o esa figura modelada en 3D que está a nuestras órdenes? ¿Quién ayuda a quién? ¿Ayudamos nosotros al personaje a que solucione sus problemas o nos ayuda él a nosotros a vivir una experiencia lúdica? ¿O es una combinación de ambos factores?

La identificación del espectador con el personaje en una película se basa ante todo en la empatía, porque depositamos en él el poder que otorga la acción. Delegamos en su saber hacer para que se nos despliegue la historia y a la vez nos sorprenda y nos hable de cómo somos como seres humanos. Por otra parte, la identificación del jugador se basa en la inmersión y de cómo el personaje hace de vehículo entre el universo, su identidad narrativa y los deseos del jugador como parte esencial de la acción de la historia. Porque sin jugador no hay avance narrativo. Entender esas diferencias y acercarlas en la medida de lo posible hará mejores juegos a través de mejores personajes que el jugador quiera interpretar y no solo utilizar como si de una muda se tratase.

En definitiva, el personaje en el videojuego es un punto de partida que debe amoldarse al jugador y no al revés. El jugador no tiene la obligación de interpretar (siempre nos encontramos con una decisión moral pensando no en las consecuencias igualmente morales, sino en las directas sobre nuestra partida). Es el juego el que debe tener una mayor capacidad narrativa para amoldarse al jugador y al mismo tiempo preservar la pureza del personaje. Siempre teniendo en cuenta que un personaje no es más que la representación de nuestra humanidad, una sombra proyectada sobre las paredes de una cueva en la que habitamos como espectadores/jugadores. Porque, como define brillantemente Stephen King en su novela Un saco de huesos, "comparado con el hombre más vulgar que camina por la faz de la tierra y proyecta allí su sombra, el más brillante de los personajes de una novela no es más que un saco de huesos".

\section{BIBLIOGRAFÍA CITADA:}

SKOLNICK, Evan. Video game Storytelling: What Every Developer Needs to Know about Narrative Techniques. New York: Watson-Guptill, 2014.

McKEE, Robert. El guion. $3^{\mathrm{a}}$ ed. Barcelona: Alba Editorial, 2004.

La narrativa del videojuego. https://www.youtube.com/watch?v=9JQgLwoRM-M https://en.wikipedia.org/wiki/Ludonarrative\#Ludonarrative_dissonance http://www.ludology.org/articles/ludology.htm 